\title{
AVALIAÇÃO DA QUALIDADE DOS SERVIÇOS EM UMA EMPRESA DE ASSISTÊNCIA TÉCNICA DE TELEFONIA MÓVEL COM A APLICAÇÃO DA ESCALA SERVQUAL
}

\section{ASSESSMENT OF THE QUALITY OF SERVICES IN A MOBILE TELEPHONE TECHNICAL ASSISTANCE COMPANY WITH THE APPLICATION OF THE SERVQUAL SCALE}

\author{
Vitor Toledo Visconti Vieira1', Danver Messias Bruno²
}

Submetido em: 14/07/2021

e27593

Aprovado em: 24/08/2021

https://doi.org/10.47820/recima21.v2i7.593

\begin{abstract}
RESUMO
A busca pela satisfação e fidelidade de clientes tem sido uma constância nas empresas prestadoras de serviços, pois são requisitos essenciais para a sobrevivência e crescimento no mercado, tendo em vista o grande número de concorrentes na atualidade. O setor de serviços tem se destacado como um dos que mais crescem e, consequentemente, mais preocupação vem sendo dispensada pelas empresas quanto ao atendimento ao cliente. Neste sentido, a percepção e a expectativa do cliente quanto ao serviço recebido tem sido foco de análise nos mais diversos segmentos. Este artigo expõe um estudo de caso que avalia a qualidade dos serviços prestados por uma empresa de assistência técnica de telefonia móvel, situada no interior do Estado de São Paulo, por meio da análise de gaps existentes entre as expectativas e percepções do cliente, com a utilização de uma adaptação da escala Servqual. Os resultados da pesquisa apontam que os serviços oferecidos pela assistência técnica estão com nível satisfatório de qualidade, no entanto existem oportunidades de melhoria para atingir a excelência.
\end{abstract}

PALAVRAS-CHAVE: Escala Servqual. Qualidade em serviços. Telefonia móvel.

\begin{abstract}
The search for customer satisfaction and loyalty has been a constant in service providers, as they are essential requirements for activities and growth in the market, considering the large number of competitors today. The service sector has stood out as one of the fastest growing, and consequently the greatest concern given by companies with regard to customer service. In this sense, the customer's perception and expectation regarding the requested service has been the focus of analysis in the most diverse segments. This article presents a case study that evaluates the quality of services provided by a mobile phone technical assistance company, located in the interior of the state of São Paulo, through the analysis of gaps between customer expectations and perceptions, with the use of an adaptation of the Servqual scale. The survey results indicate that the services offered by technical assistance have a satisfactory level of quality, however, there are excellent opportunities to achieve excellence.
\end{abstract}

KEYWORDS: Servqual Scale. Quality in services. Mobile telephony.

\section{INTRODUÇÃO}

Segundo ressaltam Tormen-Ferreira et al. (2021), independente do segmento de atuação de uma empresa, ela necessita lidar com as expectativas e satisfação de seus clientes, assim como com as estratégias de seus concorrentes. A manutenção de um negócio atrativo e competitivo envolve diversos fatores. Com o desenvolvimento de novas e acessíveis tecnologias, que se atualizam

\footnotetext{
1 Graduando no Curso de Engenharia de Produção na Universidade de Araraquara - UNIARA

2 Professor no curso de Engenharia de Produção na Universidade de Araraquara - UNIARA
} 


\section{RECIMA21 - REVISTA CIENTÍFICA MULTIDISCIPLINAR ISSN 2675-6218}

AVALIAÇÃO DA QUALIDADE DOS SERVIÇOS EM UMA EMPRESA DE ASSISTÊNCIA TÉCNICA DE TELEFONIA MÓVEL COM A APLICAÇÃO DA ESCALA SERVQUAL

rapidamente, muitas possibilidades se deslumbram no mercado, trazendo, além das oportunidades, um número maior de concorrentes e desafios.

O mercado de prestação de serviços tem crescido exponencialmente e ganhado importância, e neste negócio a qualidade percebida pelo cliente tem se tornado um grande diferencial no ganho da concorrência. Por conta disso, diversos estudos, em vários segmentos, dentre eles os de Aquino, Jerônimo e Melo (2015); Ban e Ramsaran (2017); Barroso Nascimento et al. (2021); Meira, Oliveira e Santos (2021); Melo e Morandi (2021); Petry, Pickler e Tomelin (2016); Tormen-Ferreira et al. (2021) são apresentados, buscando mensurar e investigar as variáveis que permeiam a qualidade percebida pelo cliente sobre um serviço. Apesar do grande número de estudos recentes, esta não é uma preocupação atual.

Parasuraman, Zeithaml e Berry $(1985 ; 1988)$ já dispensavam atenção ao assunto, quando definiram a qualidade do serviço como uma discrepância entre as expectativas do cliente e o serviço efetivamente prestado. E foi com base nessa definição que os autores, no enfoque de comparação, desenvolveram um instrumento baseado na expectativa e na percepção do cliente, denominada Service Quality Gap Analysis (SERVQUAL). Desde então, essa escala tem sido usada por empresas que buscam atingir, em maior grau, a satisfação dos serviços que prestam.

A escala SERVQUAL é reconhecida também por ferramenta, modelo e como instrumento, o que não desonera sua eficiência, tendo em vista a aplicação seguir um padrão. Seu uso proporciona mensurar a diferença entre expectativa e percepção, possibilitando a geração de uma pontuação, e com ela um gap para cada resposta do questionário aplicado (PARASURAMAN; ZEITHAML; BERRY, 1985). Berry (2001) ressalta a importância de lembrar sobre o valor do elemento humano no contexto da prestação de serviços e relacionamentos, tendo em vista ser a qualidade dos serviços e produtos decorrente da qualidade das pessoas.

De acordo com Dornelas (2021, p. 35), "[...] para cada empreendedor de necessidade, há 2,1 empreendedores por oportunidade, ou seja, mais de $68 \%$ dos empreendedores no Brasil empreendem por oportunidade." Em resposta a esta demanda, o estudo de Feitosa et al. (2017), informa que a crise econômica do pais nos anos de 2015 a 2016 afetou diretamente o poder de compra do consumidor na área de telefonia móvel, e se por um lado houve esse impacto, o autor ressalta sobre o aumento da demanda por reparos no segmento, demonstrando um aquecimento do setor de assistência técnica.

O número de celulares por habitante (teledensidade) alcança cifras exponenciais, segundo dados da Anatel (TELECO, 2021), no mês de abril de 2021 o Brasil fechou o mês com 242.1 milhões de celulares e densidade de 113,61 cel/100 hab. Apesar da teledensidade, Feitosa et al. (2017) afirmam que muitas vezes o consumidor, para não aderir a aparelhos de categoria inferior, por conta do status que a marca the fornece, ou mesmo no que tange a tecnologia do aparelho, ou ainda pelo custo a ser dispendido, recorre a assistência técnica antes de optar pela compra de outro aparelho.

O cenário deste estudo é a assistência técnica de aparelho móvel de uma marca conceituada nacional e internacionalmente no mercado. A justificativa pelo estudo se dá pela relevância do tema, 


\section{RECIMA21 - REVISTA CIENTÍFICA MULTIDISCIPLINAR ISSN 2675-6218}

AVALIAÇ̃̃o DA QUALIDADE DOS SERVIÇOS EM UMA EMPRESA DE ASSISTÊNCIA TÉCNICA DE TELEFONIA MÓVEL COM A APLICAÇÃO DA ESCALA SERVQUAL

diante da realidade da pandemia do Covid 19, que afetou o mundo, e vem fazendo com que as pessoas fiquem mais comedidas ao gastarem, buscando na assistência técnica a possibilidade de resolução de panes ou danos relativos a concertos, troca de peças ou mesmo de software de aparelhos móveis. Devido a esse contexto, se constrói o objetivo desse estudo, que é analisar o processo de melhoria de atendimento dos serviços prestados em uma unidade de assistência técnica de aparelho móvel, buscando estimular a melhoria nos padrões de atendimento e, consequentemente, a qualidade do serviço oferecido. Como objetivos específicos delineia-se neste estudo: buscar na literatura documentos sobre o tema; apresentar a escala Servqual; e avaliar a qualidade dos serviços prestados pela empresa do estudo.

A metodologia adotada para atingimento do proposto é de estudo de caso, descritivo e exploratório, com análise qualitativa dos dados, realizada em uma unidade de assistência técnica de celular, no interior do Estado de São Paulo, por meio da mensuração da qualidade do serviço prestado através do método SERVQUAL.

O trabalho está estruturado em sete seções, sendo que esta primeira abrange uma abordagem geral do tema, o objetivo do estudo, justificativa e metodologia. A segunda seção traz a fundamentação teórica, abarcando o que vem a ser qualidade em serviços e apresentando os conceitos e forma de aplicação da escala SERVQUAL, buscando subsídios para a aplicação prática do questionário de mensuração de qualidade. A terceira seção apresenta o método de estudo e os procedimentos operacionais. A quarta seção apresenta o estudo de caso e na sequência a discussão. Finalizando, a sexta seção compreende as considerações finais seguida das referências bibliográficas.

\section{QUALIDADE EM SERVIÇOS}

Tendo em vista, como afirmam Araújo e Gonçalves (2015 apud Perez et al., 2016), em sociedades onde existe a busca por melhores produtos e serviços, as empresas precisam priorizar pela qualidade, devendo ser essa uma ação contínua envolvendo inovação, com busca por novos caminhos, zelando pela imagem da empresa e de seu produto ou serviço, sendo essas as formas de atrair a atenção e de conquistar a liderança no mercado.

A avaliação da qualidade determina se os resultados de implementações de ações de produção conferem viabilidade, capacidade ao planejamento, o que a torna elemento balizador de ações estratégicas, por ser de extrema importância, devendo ser continua e sistêmica, tendo em vista estar atrelada a análise de aceitação dos serviços oferecidos ao cliente a longo prazo (PALADINI, 2019).

A popularização do termo "qualidade" tornou-a por diversas vezes inadequada quanto a seu efeito e uso dentro das organizações, para Paladini (2019, p. 25), sua conceituação "envolve múltiplos elementos, como diferentes níveis de importância." E, focar atenção em um deles, sem considerar os demais, pode fragilizar estrategicamente a empresa. Ainda segundo o autor, são itens fundamentais na 


\section{RECIMA21 - REVISTA CIENTÍFICA MULTIDISCIPLINAR ISSN 2675-6218}

AVALIAÇÃO DA QUALIDADE DOS SERVICCOS EM UMA EMPRESA DE ASSISTÊNCIA TÉCNICA DE TELEFONIA MÓVEL COM A APLICAÇÃO DA ESCALA SERVQUAL

avaliação da qualidade a satisfação do consumidor e o sucesso da empresa. Quanto ao grau de fidelidade e a possibilidade de tornar o cliente em consumidor, correspondem a indicativos primordiais de eficácia da gestão da qualidade. Neste sentido, o conceito de qualidade total corresponde a coordenação de todos os setores e demais áreas envolvidas na prestação do serviço na adequação do produto ao uso. Portanto, contribuições isoladas, engajadas em movimento organizado e direcionados, alcançam a excelência por meio da busca de melhoria contínua, que equivale a gestão da qualidade.

Perez et al. (2016), em busca de conceituação sobre a qualidade, pesquisou diversos estudos e construiu um quadro com algumas das principais definições da qualidade que permeiam a literatura. É possível observar que todas as definições levam em conta a satisfação dos clientes. 


\section{RECIMA21 - REVISTA CIENTÍFICA MULTIDISCIPLINAR ISSN 2675-6218}

AVALIAÇÃO DA QUALIDADE DOS SERVIÇOS EM UMA EMPRESA DE ASSISTÊNCIA TÉCNICA DE TELEFONIA MÓVEL COM A APLICAÇÃO DA ESCALA SERVQUAL Vitor Toledo Visconti Vieira, Danver Messias Bruno

QUADRO 1 - Definições de qualidade

\begin{tabular}{|c|c|}
\hline Autor & Definição \\
\hline Juran (1990. 1992) & $\begin{array}{l}\text { É um processo que deve ser aplicado continuamente com uma excelente coordenação } \\
\text { para que seja eficaz. O produto ou serviço devem ser apropriados de forma a atender as } \\
\text { expectativas do cliente. Sua trilogia (Planejamento; Controle e Melhoria;) possibilita uma } \\
\text { excelente qualidade. }\end{array}$ \\
\hline 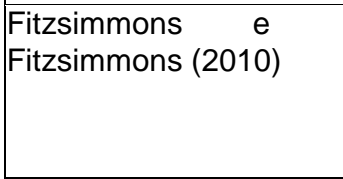 & $\begin{array}{l}\text { Definida sob três perspectiva: } \\
\text { - Qualidade surpreendente: quando excede as expectativas do cliente; } \\
\text { — Qualidade satisfatória: as expectativas do cliente são atendidas normalmente; } \\
\text { - Qualidade inaceitável: as expectativas do cliente não forem atendidas. }\end{array}$ \\
\hline $\begin{array}{l}\text { Campos (2004); } \\
\text { Abari et al. (2011) }\end{array}$ & $\begin{array}{l}\text { E um critério estável que indica um produto ou serviço que atende as necessidades do } \\
\text { consumidor de forma segura, confiável e no prazo estabelecido. }\end{array}$ \\
\hline $\begin{array}{l}\text { Crosby (1979, 1988) } \\
\text { Deming (2003); } \\
\text { Carpinetti (2012) }\end{array}$ & $\begin{array}{l}\text { É quando o produto é isento de defeitos. Para isso, todos da organização devem estar } \\
\text { cientes da necessidade de terem processos isentos de erros e fazer sempre melhorias no } \\
\text { processo. }\end{array}$ \\
\hline $\begin{array}{l}\text { Feigenbaum (1994) } \\
\text { Pinto e Alves (2012) }\end{array}$ & É \\
\hline $\begin{array}{l}\text { Ishikawa (1993); } \\
\text { Alvez e Paulista (2014) }\end{array}$ & $\begin{array}{l}\text { É vista como uma evolução do modo administrativo que exige uma mudança na maneira } \\
\text { de pensar e de agir de todos os integrantes do sistema e, principalmente, da alta } \\
\text { administração. }\end{array}$ \\
\hline $\begin{array}{l}\text { Mendonça et al. } \\
\text { (2012) }\end{array}$ & $\begin{array}{l}\text { É a satisfação do cliente ao adquirir um produto ou serviço atraído por suas } \\
\text { características determinadas. }\end{array}$ \\
\hline $\begin{array}{l}\text { Oakland (1994 citado } \\
\text { por Gobis e } \\
\text { Campanatti (2012) }\end{array}$ & $\begin{array}{l}\text { É o objetivo de todas as organizações e o melhor modo de vencer competitividade, onde } \\
\text { todas precisam da qualidade como meio para ganhar sempre novos clientes. }\end{array}$ \\
\hline $\begin{array}{l}\text { Lins, Nunes e Lima } \\
(2009)\end{array}$ & $\begin{array}{l}\text { á o fator decisivo que há no mercado competitivo para determinar a existência, } \\
\text { permanência e manutenção de uma organização. }\end{array}$ \\
\hline $\begin{array}{l}\text { Rothery (1993); } \\
\text { Anacleto, Paladim } \\
\text { Campos (2014) }\end{array}$ & $\begin{array}{l}\text { É determinada pela característica que faz com que um produto seja projetado e fabricado } \\
\text { para executar a função designada. }\end{array}$ \\
\hline $\begin{array}{l}\text { Ylãnceanu. Grunberg } \\
\text { Parlè (2009) }\end{array}$ & $\begin{array}{l}\text { É o esforço feito para atender as especificações tendo como foco o processo } € \\
\text { andamento, considerando-se sempre como objetivo e missão da organização. }\end{array}$ \\
\hline $\begin{array}{l}\text { Garan (1992): } \\
\text { Mamardes, Lourenço } \\
\text { Tontmi (2010) }\end{array}$ & $\begin{array}{l}\text { Definida por meio de cinco formas: Qualidade transcendental; Qualidade centrada no } \\
\text { produto; Qualidade com base no valor; Qualidade considerada pela produção; Qualidade } \\
\text { do ponto de vista do consumidor. }\end{array}$ \\
\hline $\begin{array}{l}\text { Meredith e Shafer } \\
(2002)\end{array}$ & $\begin{array}{l}\text { Produção com baixo preço, satisfazendo as necessidades do cliente e tomando a } \\
\text { empresa cada vez mais competitiva no mercado. }\end{array}$ \\
\hline $\begin{array}{l}\text { Maianardes, Lourenço } \\
\text { Tontini (2010) }\end{array}$ & $\begin{array}{l}\text { Definida sob duas visões: Internamente: contribuindo para a redução de desperdício, } \\
\text { aumento de produtividade e ausência de defeitos: Externamente: facilitando a conquista } \\
\text { e manutenção de clientes. }\end{array}$ \\
\hline $\begin{array}{l}\text { Dambrós et al. (2011) } \\
\text { Pelissan et al., (2011) }\end{array}$ & $\begin{array}{l}\text { Pode ser entendida como um conjunto de valores com intuito de satisfazer seus clientes, } \\
\text { porém o esforço da organização para compreender as variáveis que influenciam direta ou } \\
\text { indiretamente na satisfação de seu cliente e desenvolver ações voltadas para seu público } \\
\text { alvo. }\end{array}$ \\
\hline
\end{tabular}

Fonte: Perez et al. (2016, p. 4). 


\section{RECIMA21 - REVISTA CIENTÍFICA MULTIDISCIPLINAR ISSN 2675-6218}

AVALIAÇÃO DA QUALIDADE DOS SERVIÇOS EM UMA EMPRESA DE ASSISTÊNCIA TÉCNICA DE TELEFONIA MÓVEL COM A APLICAÇÃO DA ESCALA SERVQUAL

Para Paladini (2019), a correta definição de qualidade está ligada inicialmente a considerar a qualidade como um conjunto de atributos e elementos que compõem o produto ou serviço. Mas, reconhece que muitos autores corroboraram para construir a definição de qualidade, sendo que alguns se destacaram, os "gurus da qualidade", como são denominados. Dentre os gurus destacaram-se: William Edwards Deming (2003 apud PALADINI, 2019), definindo qualidade como um "sistema sem erros", ressalvando que os esforços em buscar a qualidade devem focar as necessidades presentes e futuras do consumidor; Joseph Moses Juran (1992 apud PALADINI, 2019), definindo "a qualidade como a adequação ao uso", sendo esse um dos principais processos gerenciais básicos para se obtenção da excelência na qualidade, e denominado de Triologia de Juran: planejamento, controle e melhoria da qualidade.

Quanto à qualidade em serviços, Gianesi e Corrêa (2010), tendo em vista ser esta formada por diversos critérios (consistência; flexibilidade; competência; credibilidade; custo; acesso; atendimento/atmosfera; e velocidade de atendimento), ressaltam que cada critério tem seu nível de importância, que é dependente do tipo de serviço oferecido, sendo a avaliação do serviço em questão percebida pelos clientes rapidamente, muitas vezes instantaneamente, quando da participação do cliente no processo de prestação de serviço.

Parasuraman, Zeithhaml e Berry (1985) afirmam que independente do segmento, é menos complexo a mensuração dos aspectos tangíveis, logo, os elementos intangíveis, como o caso da qualidade em serviços, requerem do gestor, a longo prazo, o estabelecimento de metodologias e procedimentos sistematizados que possam promover sua mensuração.

\section{SERVQUAL: escala para mensurar a qualidade dos serviços prestados}

Qualidade em serviço, segundo Parasuraman, Zeithaml e Berry (1985), é o resultado da discrepância entre a expectativa e o serviço efetivamente prestado, e quem fornece essa diferença é o cliente, por meio de sua avaliação antes e depois de receber a prestação de um serviço em questão. Diante dessa constatação, os autores, focando na comparação, desenvolveram um instrumento com base na expectativa e na percepção do cliente - a escala Service Quality Gap Analysis (SERVQUAL). Desde sua criação, a escala tem sido frequentemente utilizada por empresas que buscam atingir um elevado conceito de qualidade e de satisfação dos serviços que prestam, para isso é preciso haver um questionamento amplo dentro da empresa, buscando análise de todo processo existente, como forma de comparar o resultado com as metas da organização.

A utilização da escala SERVQUAL possibilita calcular a diferença entre a expectativa e a percepção do cliente, e no final permite gerar uma pontuação. O valor obtido ou gap, para cada resposta do questionário é a diferença entre a expectativa e a percepção, e quanto maior o índice positivo, maior e a superioridade do serviço oferecido (PARASURAMAN; ZEITHAML; BERRY, 1985). 


\section{RECIMA21 - REVISTA CIENTÍFICA MULTIDISCIPLINAR ISSN 2675-6218}

AVALIAÇÃO DA QUALIDADE DOS SERVIÇOS EM UMA EMPRESA DE ASSISTÊNCIA TÉCNICA DE TELEFONIA MÓVEL COM A APLICAÇÃO DA ESCALA SERVQUAL

A aplicação do questionário (escala SERVQUAL), contendo 22 questões, ocorre em duas etapas: Na primeira etapa registra a expectativa do cliente em relação ao serviço que será prestado, sendo sua aplicação antes de o cliente receber o atendimento; na segunda etapa, o mesmo questionário é aplicado, só que agora com o serviço já recebido, possibilitando ao cliente opinar sobre o que foi feito, desta forma registrando a percepção do cliente após o recebimento do atendimento. Ressaltando que a escala SERVQUAL pode ser aplicada em qualquer organização de serviços, de qualquer segmento ou porte (PARASURAMAN; ZEITHAML; BERRY, 1988), podendo ser adaptada de acordo com a necessidade local, para poder atender as características/necessidades de pesquisas específicas de uma organização em particular. Segundo Gianesi e Corrêa (2010), o modelo de avaliação é genérico, podendo ser aplicado também a produtos, no entanto, é mais significativo para serviços tendo em vista sua intangibilidade, isso porque quando o consumidor vê um produto tangível, enxerga sua imagem real, sendo essa a principal responsável pela formação de suas expectativas.

A avaliação dos resultados é feita por escala Likert de 7 pontos (podendo ser adaptada), na qual o número 1 corresponde à afirmativa "discordo totalmente" e o número 7 à afirmativa "concordo totalmente". A estrutura da escala original é em 5 dimensões: tangibilidade (itens do 1 ao 4 ); confiabilidade ou fiabilidade (itens de 5 a 9); atendimento ou capacidade de resposta (itens de 10 a 13); segurança (itens de 14 a 17); empatia (itens de 18 a 22).

Quanto às dimensões, segundo descrevem seus criadores, Parasuramam, Zeithaml e Berry (1988), a Tangibilidade expressa a importância das instalações físicas, dos equipamentos, do pessoal e dos materiais de comunicação; a categoria Confiabilidade, expressa a capacidade para prestar o serviço prometido de forma segura e acurada, sendo considerada a dimensão mais importante para os respondentes; Presteza, expressa a boa vontade para servir o cliente e fornecer atendimento ágil; Garantias, expressa o conhecimento e cortesia dos funcionários e suas habilidades para inspirar credibilidade e confiança; Empatia, expressa a atenção individualizada prestada ao cliente.

Barbosa et al. (2014) elaboraram, quando de estudo para aplicação da escala SERVQUAL em um posto de combustível, as hipóteses que levaram à concepção do modelo conceitual proposto:

\footnotetext{
$\mathrm{H} 1$ - Os aspectos tangíveis do serviço contribuem positivamente para a percepção da qualidade do serviço oferecido pelo posto de combustível;

H2 - A confiabilidade do serviço contribui positivamente para a percepção da qualidade do serviço oferecido pelo posto de combustível;

H3 - A presteza do serviço contribui positivamente para a percepção da qualidade do serviço oferecido pelo posto de combustível;

H4 - A segurança do serviço contribui positivamente para a percepção da qualidade do serviço oferecido pelo posto de combustível;

H5 - A empatia do serviço contribui positivamente para a percepção da qualidade do serviço oferecido pelo posto de combustível; (BARBOSA et al., 2014, p. 7).
}

Pena et al. (2013) relataram sobre a importância da dimensão confiabilidade e da menor relevância da dimensão tangibilidade, quando se trata da qualificação de serviços na percepção do cliente, levando a afirmarem sobre algumas dimensões se destacarem mais acentuadamente quando comparada com as demais, considerando o tipo de serviço oferecido. Essa constatação remete a um 


\title{
RECIMA21 - REVISTA CIENTÍFICA MULTIDISCIPLINAR ISSN 2675-6218
}

AVALIAÇ̃̃o DA QUALIDADE DOS SERVICOOS EM UMA EMPRESA DE ASSISTÊNCIA TÉCNICA DE TELEFONIA MÓVEL COM A APLICAÇÃO DA ESCALA SERVQUAL

conjunto de discrepâncias-chave ou gaps, isto é, diferenças entre o que é esperado e o que é recebido pelo cliente. Segundo Parasuraman; Berry e Zheitmal (1991), os gaps, ou lacunas podem constituíremse em um dos principais obstáculos para que os clientes percebam a prestação desses serviços como sendo de alta qualidade. Portanto, quando a percepção é maior que a expectativa, os gaps são menores e os níveis de satisfação maiores, mostrando um serviço de qualidade.

Parasuraman, Berry e Zeithaml (1988) conceituam os gaps como divergências entre empresa e cliente, consequentemente um atendimento sem qualidade. São cinco os gaps, sendo que 4 deles estão em causas relacionadas ao prestador do serviço, e 1 relacionada ao cliente. O ideal é que todos os gaps sejam eliminados, no entanto, caso essa condição não ocorra, devem ser considerados como oportunidade para melhoria da qualidade na prestação dos serviços. Os cinco gaps corporativos que usualmente são encontrados entre as expectativas e as percepções dos usuários são:

\begin{abstract}
- Gap 1: refere-se às expectativas dos consumidores e à percepção da gerência com relação a elas. Os prestadores de serviço nem sempre entendem que requisitos conotam excelência da qualidade para os consumidores;

- Gap 2: está nas especificações da qualidade dos serviços definidas pela tradução das percepções que a gerência tem das expectativas dos usuários. Essa discrepância deve-se à falta de especificação da oferta ajustada aos desejos dos consumidores; - Gap 3: diz respeito ao desempenho real da prestação do serviço frente às especificações previamente estabelecidas;

- Gap 4: relaciona o serviço realmente fornecido e as comunicações externas (especificações do serviço anunciadas na mídia ou outros canais de comunicação); - Gap 5: foi estabelecida como uma função das quatro lacunas anteriores, isto é, gap 5 = f [gap 1, gap 2, gap 3, gap 4]. (PENA et al., 2013, p. 1237).
\end{abstract}

Segundo Pena et al. (2013, p. 1238), "Na ausência de medidas objetivas, pode-se considerar apropriado que a avaliação seja realizada pela mensuração da percepção do serviço pelo usuário." A figura 1 apresenta um modelo gap da qualidade dos serviços. 


\section{RECIMA21 - REVISTA CIENTÍFICA MULTIDISCIPLINAR ISSN 2675-6218}

AVALIAÇÃO DA QUALIDADE DOS SERVIÇOS EM UMA EMPRESA DE ASSISTÊNCIA TÉCNICA DE TELEFONIA MÓVEL COM A APLICAÇÃO DA ESCALA SERVQUAL

FIGURA 1 - Modelo gaps da qualidade dos serviços

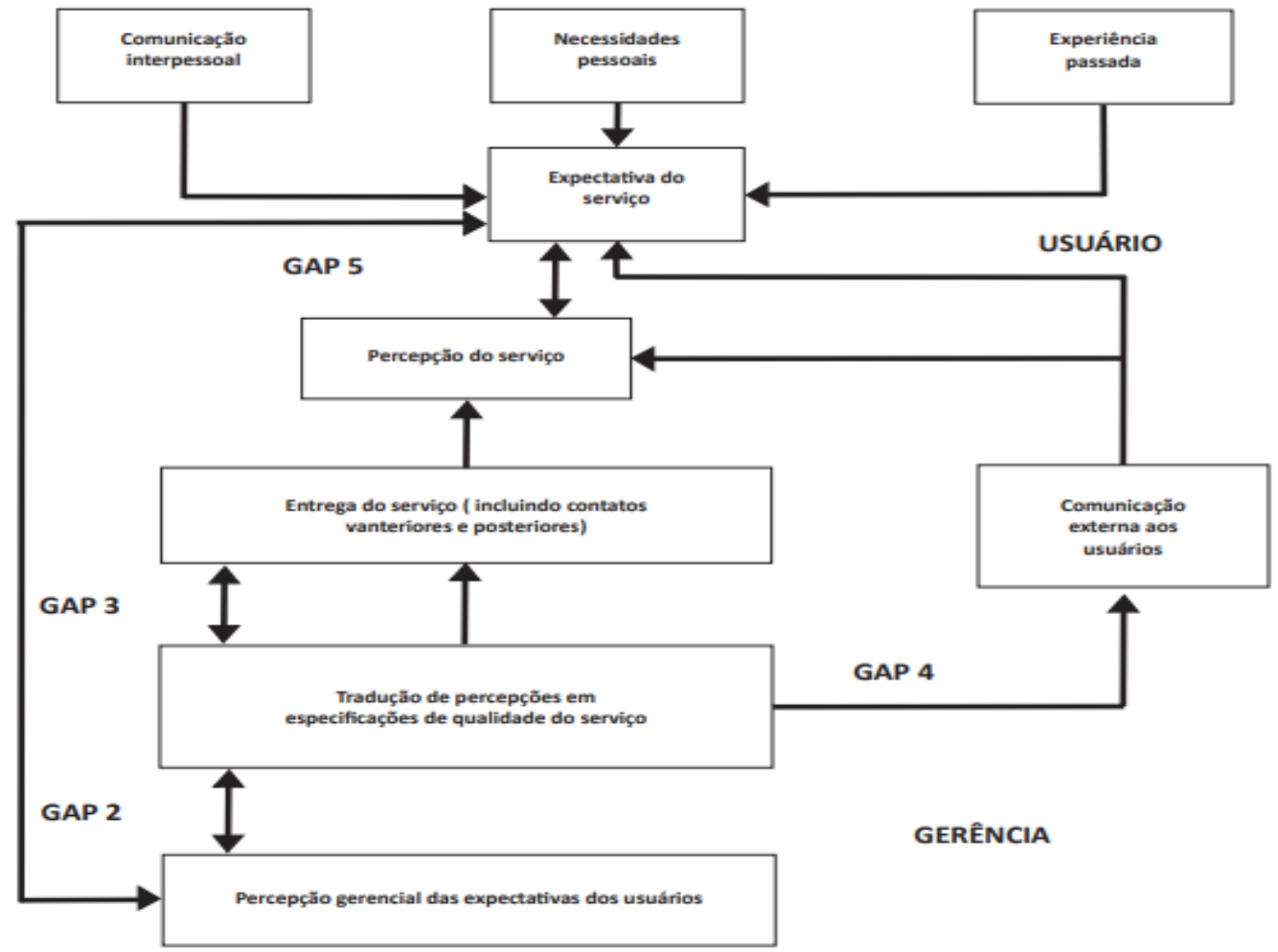

Fonte: Pena et al. (2013, p. 1238).

Sobre as medidas dos gaps, Pena et al. (2003) ensinam que essa é calculada entre as pontuações nas 5 dimensões, possibilitando detectar a superioridade do serviço em questão, sendo a chave que assegura a boa qualidade aparente quando a percepção excede a expectativa do cliente.

Diante das possibilidades de adaptação para diversos segmentos, apresentamos neste estudo a aplicação da escala SERVQUAL em uma unidade de assistência técnica de telefonia móvel.

\section{MÉTODO}

Quanto à metodologia, trata-se de um estudo de levantamento bibliográfico e tem por natureza a pesquisa qualitativa, e quanto aos objetivos é uma pesquisa descritiva, que descreve e envolve técnicas e coleta de dados por observação sistemática. O método é aplicação de estudo de caso.

A aplicação da escala SERVQUAL permitiu analisar a percepção dos clientes da assistência técnica quanto ao serviço de atendimento oferecido e como o serviço realmente ocorre, possibilitando a coleta de informações para melhorar os pontos fracos e buscar a excelência por meio do atingimento da satisfação de seus clientes.

O ambiente de pesquisa é uma empresa, inaugurada no ano de 2017, que surgiu da demanda de vendas de celulares de uma marca específica, com prestação de serviços de assistência técnica de 


\section{RECIMA21 - REVISTA CIENTÍFICA MULTIDISCIPLINAR ISSN 2675-6218}

AVALIAÇ̃̃o DA QUALIDADE DOS SERVIÇOS EM UMA EMPRESA DE ASSISTÊNCIA TÉCNICA DE TELEFONIA MÓVEL COM A APLICAÇÃO DA ESCALA SERVQUAL Vitor Toledo Visconti Vieira, Danver Messias Bruno

telefonia móvel, caracterizada como uma loja de conveniência, instalada junto a um posto de combustível, na cidade de Araraquara, interior do estado de São Paulo.

O estudo de caso foi dividido em quatro etapas:

Etapa 1- Desenvolvimento do questionário: adaptou-se a escala SERVQUAL desenvolvida por Parasuraman, Berry e Zeithaml (1985), utilizando uma pontuação likert de 0 a 5, na qual o número 1 discordo totalmente; 2 - discordo; 3 - discordo parcialmente; 4 -concordo parcialmente; 5 - concordo totalmente. A construção do questionário tem por base cinco dimensões: tangibilidade, itens do 1 ao 4; confiabilidade, itens de 5 a 9; presteza itens de 10 a 13; segurança, itens de 14 a 17; empatia, itens de 18 a 22, sendo adaptado para a natureza do serviço avaliado e composto por duas partes com 22 itens cada.

Etapa 2 - Aplicação do questionário - como descrito na literatura, a primeira aplicação do questionário buscou detectar as "Expectativas" dos clientes quanto ao serviço prestado por uma empresa de assistência técnica de telefonia móvel, a segunda parte, as "Perspectivas" destes clientes quanto o desempenho do serviço recebido. Esta aplicação gerou uma pontuação para cada quesito a ser analisado numa escala de 1 a 5. Esta etapa foi realizada no período de 01 a 21 de junho de 2021, e ao receber o questionário, o cliente foi esclarecido sobre a aplicação do mesmo, solicitando sua participação. O questionário foi aplicado a uma amostra de 10 clientes da empresa, que buscaram pelos serviços de assistência técnica, e concordaram em participar da pesquisa, mediante informação sobre o objetivo de melhorar 0 atendimento. Após orientados sobre responder inicialmente 0 questionário referentes às expectativas e após o recebimento do serviço, responderem o questionário tendo foco na percepção do que foi recebido, estando o aplicador a disposição para esclarecimentos.

Etapa 3 - Identificação de itens críticos: a Tabela 1 apresenta os resultados relacionados, a Percepção, a Expectativa e os Gaps, utilizando e seguindo cada item, segundo os clientes da empresa. O gap representa a lacuna entre a diferença entre o ideal Percepção e Expectativa, que corresponde ao que foi recebido pelo cliente. Resultados negativos representam que as percepções estão abaixo das expectativas, da mesma forma, resultados positivos representam que os serviços estão acima do esperado.

Etapa 4 - Análise das dimensões (Expectativa e Perspectiva): os níveis altos para expectativas, são considerados respostas entre os valores 4 e 5, demonstrando a qualidade, quantificada por meio dos gaps existentes entre as expectativas e as percepções que o cliente tem do real serviço oferecido. Com isso foi possível detectar a superioridade ou não do serviço em questão.

Ao término da aplicação do questionário e coleta de dados, procedeu-se a análise dos dados. Para tabulação, os dados (respostas dos clientes) foram inseridos no programa Excel para obtenção das médias, que foi mediante a comparação das pontuações dadas pelos clientes nas dimensões (Expectativa e Perspectiva), confrontando o que a empresa oferece e o que poderia ser implantando para melhorias no atendimento, onde foi feito o cálculo da média Ex e Px, que correspondem respectivamente a diferença entre expectativa e percepção (gaps). 


\section{RECIMA21 - REVISTA CIENTÍFICA MULTIDISCIPLINAR ISSN 2675-6218}

AVALIAÇ̃̃o DA QUALIDADE DOS SERVIÇOS EM UMA EMPRESA DE ASSISTÊNCIA TÉCNICA DE TELEFONIA MÓVEL COM A APLICAÇÃO DA ESCALA SERVQUAL Vitor Toledo Visconti Vieira, Danver Messias Bruno

\section{RESULTADOS}

A análise das dimensões possibilitou a compreensão dos níveis de satisfação dos clientes e os gaps da qualidade, demonstrando áreas que precisam de maior atenção na empresa. A Tabela 1 apresenta os resultados da aplicação da escala.

TABELA 1 - Resultados da Percepção, a Expectativa e o Gap, segundo os clientes de uma unidade de assistência técnica de Telefonia móvel

\begin{tabular}{|c|c|c|c|c|c|}
\hline Dimensão & № & Pergunta da área & $\mathbf{P x}$ & Ex & Gaps \\
\hline \multirow{4}{*}{ Tangibilidade } & 1 & O equipamento é atualizado & 4,60 & 4.70 & 0,10 \\
\hline & 2 & $\begin{array}{l}\text { As instalações físicas são } \\
\text { visualmente atraentes }\end{array}$ & 4,20 & 4,10 & $-0,10$ \\
\hline & 3 & $\begin{array}{l}\text { Os empregados estão bem- } \\
\text { vestidos/arrumados }\end{array}$ & 4,80 & 3,90 & $-0,90$ \\
\hline & 4 & $\begin{array}{l}\text { A aparência das instalações físicas } \\
\text { é condizente com o tipo de negócio } \\
\text { da prestadora de serviços }\end{array}$ & 4,40 & 4,80 & 0,40 \\
\hline \multicolumn{5}{|c|}{ Média geral final da dimensão } & $-0,13$ \\
\hline \multirow{5}{*}{ Confiabilidade } & 5 & $\begin{array}{l}\text { A empresa atende os cronogramas } \\
\text { prometidos (envio de propostas, } \\
\text { orçamentos, contato com o cliente) }\end{array}$ & 4,30 & 4,50 & 0,20 \\
\hline & 6 & $\begin{array}{l}\text { A empresa tem interesse em } \\
\text { resolver os problemas do cliente }\end{array}$ & 4,20 & 4,60 & 0,40 \\
\hline & 7 & $\begin{array}{l}\text { Os profissionais da empresa são } \\
\text { bem qualificados }\end{array}$ & 4,80 & 4,60 & $-0,20$ \\
\hline & 8 & $\begin{array}{l}\text { A empresa presta o serviço na data } \\
\text { combinada }\end{array}$ & 4,20 & 4,50 & 0,30 \\
\hline & 9 & $\begin{array}{l}\text { A empresa mantém registros de } \\
\text { tudo que envolve o serviço }\end{array}$ & 4,60 & 4.60 & 0,00 \\
\hline \multicolumn{5}{|c|}{ Média geral final da dimensão } & 0,14 \\
\hline \multirow{4}{*}{ Presteza } & 10 & $\begin{array}{l}\text { Os colaboradores informam com } \\
\text { precisão a data da prestação do } \\
\text { serviço }\end{array}$ & 4,10 & 3,60 & $-0,50$ \\
\hline & 11 & $\begin{array}{l}\text { Os colaboradores atendem } \\
\text { rapidamente as demandas do } \\
\text { cliente }\end{array}$ & 3,80 & 4,40 & 0,60 \\
\hline & 12 & $\begin{array}{l}\text { Os colaboradores estão sempre } \\
\text { dispostos a ajudar o cliente }\end{array}$ & 4,00 & 4,50 & 0,50 \\
\hline & 13 & $\begin{array}{l}\text { Os colaboradores estão sempre } \\
\text { ocupados demais para atender o } \\
\text { cliente }\end{array}$ & 2.60 & 2,40 & $-0,20$ \\
\hline \multicolumn{5}{|c|}{ Média geral final da dimensão } & 0,10 \\
\hline \multirow{4}{*}{ Segurança } & 14 & Os colaboradores são confiáveis & 3,70 & 4,90 & 1,20 \\
\hline & 15 & $\begin{array}{l}\text { Os clientes sentem-se seguros ao } \\
\text { negociar com os colaboradores }\end{array}$ & 3,70 & 4,50 & 0.80 \\
\hline & 16 & $\begin{array}{l}\text { Os colaboradores são } \\
\text { educados/gentis }\end{array}$ & 4,10 & 4,90 & 0,80 \\
\hline & 17 & Os colaboradores sabem & 4,00 & 4,70 & 0,70 \\
\hline
\end{tabular}




\section{RECIMA21 - REVISTA CIENTÍFICA MULTIDISCIPLINAR ISSN 2675-6218}

AVALIAÇ̃̃o DA QUALIDADE DOS SERVICCOS EM UMA EMPRESA DE ASSISTÊNCIA TÉCNICA DE TELEFONIA MÓVEL COM A APLICAÇÃO DA ESCALA SERVQUAL Vitor Toledo Visconti Vieira, Danver Messias Bruno

\begin{tabular}{|l|c|l|c|c|c|}
\cline { 2 - 5 } & \multicolumn{3}{|c|}{ Mesponder às perguntas do cliente } & & $\mathbf{0 , 8 8}$ \\
\hline \multirow{5}{*}{ Empatia } & 18 & $\begin{array}{l}\text { A empresa dá a cada cliente } \\
\text { atenção individualizada }\end{array}$ & 4,50 & 3,90 & $-0,60$ \\
\cline { 2 - 5 } & 19 & $\begin{array}{l}\text { Os colaboradores dão atenção } \\
\text { individualizada a cada cliente }\end{array}$ & 4,00 & 4,10 & 0,10 \\
\cline { 2 - 6 } & 20 & $\begin{array}{l}\text { Os colaboradores compreendem } \\
\text { plenamente as } \\
\text { necessidades/sentimentos do } \\
\text { cliente }\end{array}$ & 3,50 & 4,40 & 0,90 \\
\cline { 2 - 6 } & 21 & $\begin{array}{l}\text { Os colaboradores carregam } \\
\text { consigo os interesses do cliente }\end{array}$ & 3,30 & 4,20 & 0,90 \\
\cline { 2 - 6 } & 22 & $\begin{array}{l}\text { A empresa funciona em horário(s) } \\
\text { conveniente(s) para o cliente }\end{array}$ & 4,30 & 4,90 & 0,60 \\
\hline
\end{tabular}

Fonte: Elaborado pelo autor.

Níveis positivos mostraram que a qualidade do serviço oferecido pela assistência técnica está acima do esperado, em contrapartida, os níveis negativos evidenciaram a necessidade de atenção e resolução. A Tabela 1 expôs as médias que estão entre 2,40 e 4,90, sendo que nenhuma das dimensões atingiu a pontuação máxima, mostrando alguns pontos críticos a serem repensados, segundo a pontuação dada pelos clientes.

\section{DISCUSSÂO}

Conforme demonstra resultado da Tabela 1, a dimensão tangibilidade apresenta média negativa de $-0,13$, sendo o gap a diferença entre a percepção e a expectativa, demonstrando que alguns itens ainda não estão como o cliente gostaria. A esse respeito, no item 4 , quando trata da aparência da empresa ser condizente com o negócio, o gap resultou em 0,40 , o que leva a compreender que os clientes esperam mais da empresa em termos de estrutura física. Ainda assim, a tangibilidade é a dimensão que melhor pontuação recebeu, tendo em vista a média geral dessa dimensão ter sido negativa. Ou seja, mais próximo do serviço com excelência.

Considerando os resultados e discussão dos 5 Gaps, na tangibilidade dos serviços prestados, ou seja, mensura a qualidade dos recursos físicos, abarcando a infraestrutura, equipamentos usados e aparência dos funcionários, e neste o estudo teve como resultado gap de $-0,13$, a menor diferença entre a percepção e expectativa do cliente em relação as demais dimensões. Neste item podemos relatar que o estacionamento da empresa é compartilhado com outra empresa, pois tratar-se de uma loja de conveniência instalada junto a um posto de combustível. Quanto a uniformização dos funcionários, apesar de ter um uniforme padrão, muitas vezes não há cumprimento em vesti-lo pelos funcionários. A pontuação quanto a aparência da loja pode ser justamente por conta de atender uma clientela específica, que espera mais por conta da marca do produto que a assistência atende. 


\section{RECIMA21 - REVISTA CIENTÍFICA MULTIDISCIPLINAR ISSN 2675-6218}

AVALIAÇÃO DA QUALIDADE DOS SERVIÇOS EM UMA EMPRESA DE ASSISTÊNCIA TÉCNICA DE TELEFONIA MÓVEL COM A APLICAÇÃO DA ESCALA SERVQUAL

Na dimensão Confiabilidade, que avalia capacidade da empresa de assistência técnica de telefonia móvel em realizar o serviço de forma confiável, precisa e conforme o que foi prometido, que corresponde que o prometido está sendo efetuado, pontuando 0,14. Sobre esta dimensão, a empresa busca respeitar os prazos e cronogramas, no entanto, alguns reparos exigem troca de peças, e isso requer uma logística, tendo em vista a empresa não manter estoques de algumas peças, que muitas vezes são importadas, e também a entrega de alguns componentes e reparos ficam a encargo da própria central da marca (como recuperação de conta perdida, senha).

Na dimensão Presteza, avaliando a rapidez da empresa em prestar o serviço e sua disposição em solucionar dúvidas, a pontuação média da dimensão foi de 0,10 . Quanto à esta dimensão, os funcionários são treinados para oferecer um serviço especializado e buscam oferecer sempre a transparência no serviço.

$\mathrm{Na}$ dimensão segurança, que indica a competência da assistência técnica ao transmitir confiança e segurança aos clientes pontuou 0,88. Esta dimensão também é consequência do treinamento que os funcionários recebem quanto a forma de atendimento.

Por fim, a dimensão empatia, pontuou 0,38, que corresponde a quanto o atendimento é personalizado e individualizado, conforme a necessidade do cliente. Por ser uma assistência técnica especializada, a empresa prestadora de serviço não tem a liberdade de efetuar alguns tipos de reparos, de certa forma limitando o atendimento.

Analisando os resultados e discussão dos 5 Gaps, é possível concluir que a empresa de forma geral precisa de uma reestruturação, tendo em vista todos as dimensões gerarem gaps, mostrando a divergência com o que é oferecido e com o que o cliente entende como qualidade recebida.

\section{CONSIDERAÇÕES FINAIS}

A escala SERVQUAL é de fácil aplicação, possibilita confrontar o que a empresa oferece e como o cliente percebe o que foi oferecido, permitindo uma análise para planejamento e reestruturação para melhor atender. No entanto, um dos pontos preocupantes, ou problema operacional da aplicação da escala é o tempo dispendido pelo cliente. O questionário requer um tempo longo, tendo em vista ser aplicado duas vezes (mensurar expectativa e mensurar percepção), tornando a escala complexa e por vezes cansativas para os clientes, levando o próprio aplicador do questionário a limitar o número de respondentes, como forma de não incomodar o cliente.

Com os resultados da aplicação da ferramenta SERVQUAL, a empresa conseguiu observar os seus pontos positivos e negativos, por meio do levantado de algumas informações importantes para a melhoria da qualidade e satisfação do cliente. Esses dados puderam ser obtidos por meio da pontuação na dimensão Segurança, que mostrou maior alerta. Comparando o que é expectativa com o que é percepção, pode-se verificar a importância que os clientes dão a esses aspectos para obtenção da qualidade do serviço e, mostrando onde é possível melhorar. Para atender a dimensão 


\section{RECIMA21 - REVISTA CIENTÍFICA MULTIDISCIPLINAR ISSN 2675-6218}

AVALIAÇÃO DA QUALIDADE DOS SERVIÇOS EM UMA EMPRESA DE ASSISTÊNCIA TÉCNICA DE TELEFONIA MÓVEL COM A APLICAÇÃO DA ESCALA SERVQUAL

segurança, julgamos necessário que todos os colaboradores participem de reuniões e treinamentos, com exposição de ideias, como forma de buscar a resolução e correção deste gap. Estes dados serão levados em conta pela empresa e serão analisados para certas melhorias.

Quanto aos resultados obtidos, é preciso levar em conta que a empresa presta serviços especializados, direcionados à uma classe específica de clientes, considerados, por conta da marca do produto, de classe média a alta, de poder aquisitivo privilegiado, e talvez, por conta disso mais exigente.

Ainda assim, os resultados devem ser considerados, como forma de planejar novas ações para sanar os pontos fracos e aumentar os pontos positivos encontrados, tendo em vista que manter um cliente é mais fácil que conquistar novos, e que esse mesmo cliente pode garantir novos, conforme o tipo de comentários que praticar.

\section{REFERÊNCIAS}

AQUINO, J. T.; JERONIMO, T. B.; MELO, F. J. C. Avaliação da qualidade em serviço de um hotel pelo método SERVPERF. Revista Pensamento Contemporâneo em Administração, Rio de Janeiro, v. 9, n. 1, p. 124-141, 2019. Disponível em: http://www.spell.org.br/documentos/ver/35215 Acesso em: 11 jun. 2021.

BAN, J.; RAMSARAN, R. R. An exploratory examination of service quality attributes in the Ecotourism Industry. Journal of Travel \& Tourism Marketing, London, v. 34, n.1, p. 132-148, 2017. Available from: https://www.tandfonline.com/doi/abs/10.1080/10548408.2016.1141155?journalCode=wttm20 Access: 10 jun. 2021.

BARBOSA, F. L. S.; RABEL NETO, A.; MOREIRA, R. N.; BIZARRIA, F. P. A. As dimensões da escala servqual na qualidade percebida por clientes de postos de combustível: um estudo em Teresina-PI. In: X CONGRESSO NACIONAL DE EXCELÊNCIA EM GESTÃO, 10., Rio de Janeiro, 2014. [Anais...]. Rio de Janeiro, FIRJAN, 2014. 20 p. Disponível em:

https://www.inovarse.org/sites/default/files/T14 0112 3.pdf Acesso em: 16 jun. 2021.

BARROSO NASCIMENTO, F.; RIBEIRO, P. P. D.; CHALUB, S. R. S.; RODRIGUES, A. M.; MARTINS, K. S. A.; SANTOS. J. L. D.; KOGA, G. N. C.; SOARES, M. C. C. X. Estudo da mensuração de um indicador de qualidade em centro cirúrgico: tempo de turnover e nível de desempenho. Brazilian Journal of Health Review, Curitiba, v. 4, n. 2, p. 6553-6567, mar./abr. 2021. Disponível em: https://www.brazilianjournals.com/index.php/BJHR/article/view/27087 Acesso em: 16 jun. 2021.

BERRY, L. L. Descobrindo a essência do serviço: os nove geradores de sucesso sustentável nos negócios. Tradução Bazán Tecnologia e linguística. Rio de Janeiro: Qualitymark, 2001.

DORNELAS, J. C. A. Empreendedorismo: transformando ideias em negócios. 8. ed. São Paulo: Empreende, 2021.

FEITOSA, E.; NUNES, R.; PAULA, J.; MARCONDES, S.; SANTANA, P. S. Empreendedorismo: como as assistências técnicas de telefonia móvel sobrevivem em meio à crise econômica. Educação, Gestão e Sociedade: revista da Faculdade Eça de Queirós, Jandira-SP, Ano 7, n. 27, p. 1-14, ago. 2017. Disponível em: http://uniesp.edu.br/sites/ biblioteca/revistas/20170919090629.pdf. Acesso em: 16 jun. 2021.

GIANESI, I. G. N.; CORRÊA, H. L. Administração estratégica de serviços: operações para satisfação do cliente. São Paulo: Atlas, 2010. 

ISSN 2675-6218

AVALIAÇÃO DA QUALIDADE DOS SERVIÇOS EM UMA EMPRESA DE ASSISTÊNCIA TÉCNICA DE TELEFONIA MÓVEL COM A APLICAÇÃO DA ESCALA SERVQUAL

ISMAIL, A. B.; JIANG, H. Comparing Service quality for long - haul low - cost carriers: Case for Asia and Australia routes. Journal of Quality Assurance In Hospitality And Tourism, London, v. 20, n. 6, 2019. Available from: https://www.tandfonline.com/doi/abs/10.1080/1528008X.2019.1580660 Access: 10 jun. 2021.

MEIRA, S. R. C.; OLIVEIRA, A. S. B.; SANTOS, C. O. A contribuição da auditoria para a qualidade da gestão dos serviços de saúde. Brazilian Journals of Business, Curitiba, v. 3, n. 1, p. 1021-1033, jan./mar. 2021. Disponível em: https://www.brazilianjournals.com/index.php/BJB/article/download/26310/20861. Acesso em: 16 jun. 2021.

MELO, H. P.; MORANDI, L. Mensurar o trabalho não pago no Brasil: uma proposta metodológica. Economia e Sociedade, Campinas. v. 30, n. 1, p. 187-210, jan./abr. 2021. Disponível em: https://www.scielo.br///ecos/a/mgKPK77mpq64FJXx7mBrDXQ/?lang=pt\&format=pdf. Acesso em: 16 jun. 2021.

PALADINI, E. P. Gestão da qualidade: teoria e prática. 4. ed. São Paulo: Atlas, 2019.

PARASURAMAN, A.; BERRY, L. L.; ZHEITMAL, V. A. Refinement and reassessement of the SERVQUAL dimensions. Journal of Retailing, New York, v. 67, n. 4, p. 420-50, 1991. Available from: https://www.researchgate.net/publication/304344168 Refinement and reassessment of the SERVQ UAL scale/link/5919b21eaca2722d7cfe633d/download Access: 19 jun. 2021.

PARASURAMAN, A.; ZEITHAML, V. A.; BERRY, L. L. A conceptual model of service quality and its implications for future research. Journal of Marketing, Chicago, v. 49, p. 41-50, 1985. Available from: http://sistemas-humano-computacionais.wdfiles.com/local--files/capitulo\%3Asistemas-deservico/ServQual.PDF Access: 10 jun. 2021.

PARASURAMAN, A.; ZEITHAML, V. A.; BERRY, L. L. Servqual: A multiple-ltem Scale for Measuring Consumer Perceptions of Service Quality. Journal of Retailing, New York, v. 64, n.1, 1988. Available from: http://howardesign.com/exp/service/cite.php?id=10 Access: 10 jun. 2021.

PENA, M. M.; SILVA, E. M. S.; TRONCHIN, D. M. R.; MELLEIRO, M. M. O emprego do modelo de qualidade de Parasuraman, Zeithaml e Berry em serviços de saúde. Rev Esc Enferm USP, São Paulo, v. 47, n. 5, p. 1235-40, 2013. Disponível em: http://www.scielo.br/pdf/reeusp/v47n5/pt 0080-6234reeusp-47-05-1227.pdf Acesso em: 20 jun. 2021.

PEREZ, V. V.; BATISTA, M. R. P.; SANTOS, W.; DIAS, E. D.; SILVA, A. S. B. Qualidade e gestão da qualidade: a percepção de discentes formandos da FEPI. In: ENCONTRO NACIONAL DE ENGENHARIA DE PRODUCÃO. 36., João Pessoa, PB. 2016. [Anais...]. João Pessoa: Abepro, 2016. 25 p. Disponível em: http://www.abepro.org.br/biblioteca/TN STO 235368 30150.pdf Acesso em: 11 jun. 2021.

PETRY, T. E.; PICKLER, C. M.; TOMELIN, C. A. Prestados nos hotéis de Florianópolis: uma análise a partir do conteúdo gerado no website booking.com. Turismo - Visão e Ação, Itajaí. v. 18, n. 2, p. 327352, maio. 2016. Disponível em: https://siaiap32.univali.br/seer/index.php/rtva/article/view/8870 Acesso em: 11 jun. 2021.

TELECO. INTELIGÊNCIA EM TELECOMUNICAÇÕES. Estatísticas de celulares no Brasil. 10 jun. 2021. Disponível em: https://www.teleco.com.br/ncel.asp 2021 Acesso em: 11 jun. 2021.

TORMEN-FERREIRA, J. A.; LUCATELLI, F.; BEHLING, H. P.; ANDRADE, M. A. R. Qualidade percebida nos serviços do Parque Unipraias - SC: a percepção dos clientes nacionais. Observatório de Inovação do Turismo - Revista Acadêmica, Rio de Janeiro, v. 15, n. 1, abr. 2021. Disponível em: http://publicacoes.unigranrio.edu.br/index.php/raoit/article/view/6270/3391 Acesso em: 16 jun. 2021. 